Original scientific paper

UDK: 355.02:061.1 EU; 327.56

DOI: 10.11643 issn.2217-995X182SPV87

Received: 2 October 2017 / Accepted: 17 August 2018

\title{
Local Ownership, Inclusivity and Civil-Military Synergy in EU External Action: The Case of EU Support to Security Sector Reforms in Mali
}

\author{
GABRIËLLA VOGELAAR* \\ GPPAC, The Netherlands
}

\begin{abstract}
The evolution of the European Union (EU) as a security and peacebuilding actor raises questions as to its identity as a largely civilian power alongside the development of its military capabilities. Specifically, a key challenge lies in how its civilian and military capabilities relate to each other as they develop, with increasing expectations from the EU to act effectively across its peacebuilding and conflict prevention interventions. The EU aims to do more to link top-down and bottom-up approaches, but there is currently a lack of focus on the latter. In exploring the challenges and opportunities for the EU to enhance its potential for civil-military synergies in crisis management, the paper takes a holistic whole-of-society perspective, asking questions about the level of inclusivity and local ownership in its approaches. The paper takes a closer look at the European Union Training Mission (EUTM) and European Union Capacity Building Mission in Mali (EUCAP Sahel Mali) as a specific case. Based on the findings, this paper argues the EU could be more effective, especially at the operational level, by taking a more bottom-up approach in the areas of designing, planning, monitoring and evaluating interventions. The EU will need to find ways to better embed its interventions in local realities, for instance by working with local civil society in the EU's security sector reform efforts, and offering platforms for more civilian oversight and feedback mechanisms. Only then, with a stronger focus on the inclusivity and local ownership aspects of civil and military action of the EU, will it be able to better address the 'intangible aspects' of security sector reform.
\end{abstract}

Keywords: EU, whole-of-society, civil-military synergy, local ownership, inclusivity, peacebuilding.

\section{Introduction}

Civil-military synergy is becoming an increasingly important area for the European Union (EU) in further developing its security and defence capabilities. As the latter are evolving as we speak, it is not yet fully clear what civil-military synergy will look like in the future. Considering how the EU can drive its integrated approach further through civil-military synergy, the area of capacity building of local actors in security sector reform ${ }^{1}$ (SSR) is

1 Or security sector 'development', as some countries prefer to describe it.

*g.vogelaar@gppac.net 
especially relevant. Taking a whole-of-society perspective, this article discusses two main angles, the one of local ownership and that of inclusivity. It looks at ways the EU could engage, empower and support the "civil" part in a broad sense, especially through its engagements with (local) civil society, as well as at the specific role and contribution that civil society and non-governmental organisations (NGOs) can make to the EU's efforts. It focuses on the specific case of the EU's supported security sector capacity-building efforts in Mali.

The article aims to answer the following questions: what are the gaps or tensions between the EU's stated ambitions and policies on local ownership and inclusivity of its peacebuilding and crisis management interventions - both civil and military - and what is found in practice at the operational level? What are the main challenges and limitations of the EU supported security sector reform and capacity building efforts in Mali, with regard to operationalising local ownership and inclusivity in the civil-military domain? What are the opportunities for the EU to overcome some of these challenges and areas in which the EU can enhance local ownership and inclusivity in its security sector interventions?

Considering how the concept of civil-military synergy in EU action is evolving, this article makes a case for a stronger focus on the inclusivity and local ownership aspects of civil and military action of the EU, to be able to better address the 'intangible aspects' of security sector reform, as shall be argued below. Taking a whole-of-society perspective, this article focuses on the EU's peacebuilding and conflict prevention efforts in Mali, and in particular on the issues around local ownership in the sphere of security sector reform. Mali was selected because the EU has both civilian and military capacity building missions there, in a context that is linked to the security-development nexus; the EU's internal and external security concerns are present; and there are some key findings on the efforts to work towards local ownership. In Mali, insecurity has its roots in the marginalisation of groups - or the perception thereof, underlining the need for inclusive approaches. Taking into account numerous strategies that are implemented in the Sahel by various actors (the United Nations, the EU, and others), it has become clear that even though security and development have been increasingly linked, they have not yet brought about the desired stability. ${ }^{2}$

The article draws on several sources of information: primary sources are based on a set of interviews and engagements by the author both in Europe and Mali. In addition to this, secondary literature was consulted. The article is largely based on findings from 2016 and 2017 that are part of the EU-funded Horizon 2020 project 'Whole of Society Conflict Prevention and Peacebuilding' (WOSCAP). ${ }^{3}$ Hence, the article takes a whole-of-society perspective as the conceptual framework. The article also draws on views and experiences shared by practitioners - from civilian, military, and justice backgrounds - on civil-

2 Tobie 2017, 1.

3 See www.woscap.eu 
military synergies at the operational level, debated at several meetings. ${ }^{4}$ In addition, the author held11 interviews with EU representatives at the European External Action Service (EEAS), the European Commission's Directorate-General for International Cooperation and Development (DEVCO), as well as with persons involved in the United Nations (UN) and EU missions in Mali, notably MINUSMA, ${ }^{5}$ the EU Training Mission (EUTM) to Mali and the EU Delegation to Mali. Furthermore, it refers to a recent study on the EU's peacebuilding capabilities in Mali, conducted by the Université des Sciences Juridiques et Politiques de Bamako (USJPB), as part of the WOSCAP project. Moreover, the author visited Mali three times in the context of coordinating a peacebuilding project in Mali, speaking to several governmental actors. This included a visit to the EUTM training camp in Koulikoro, Mali, in January 2014. Besides this, the author provided preparatory seminars to armed forces to be deployed in the United Nations Multidimensional Integrated Stabilisation Mission in Mali (MINUSMA) as part of five training programmes of the Dutch Ministry of Defence between the years 2014 and 2017.

The following section of this article will discuss the whole-of-society approach and outline the concepts of local ownership, inclusivity and how they have been used in the EU's peacebuilding context and the EU's relationship to civil society. The third section will discuss the notion of civil-military synergy and how it is developing in the context of the EU's crisis management and conflict prevention. The fourth section takes a closer look at how local ownership and inclusivity play out in the EU's civilian and military Common Security and Defence Policy (CSDP) missions in Mali, EUTM and EUCAP Sahel. Drawing on this, the final sections outline the EU's main challenges, followed by identifying the areas in which the EU has the opportunity to work on its ambitions for local ownership within the security sector.

The article looks not only at the EU as a crisis management actor in the narrow sense, but takes into account its ambitions for an integrated approach to conflicts and crises, including conflict prevention and different stages of the conflict cycle.

4 This section of the paper is based on discussions that were held with practitioners from both civil and military sides of affairs at the WOSCAP round table on Civil-Military Synergy held on 26 September 2016 at Global Partnership for the Prevention of Armed Conflict (GPPAC), the Hague. The meeting report can be found at https://www.woscap.eu/documents/131298403/131299900/ Deliverable+4.4+-+WOSCAP+-+Community+of+Practice+Event+on+Civil-Military+Synergies_final.pdf/b10114cf-52e2-441b-9acd-2892c689eaad.

5 The United Nations Multidimensional Integrated Stabilisation Mission in Mali. 


\section{Whole of Society, Inclusivity and Local Ownership}

The article takes a whole-of-society approach ${ }^{6}$ to analyse local ownership and inclusivity in the EU's peacebuilding efforts. The whole-of-society approach derives from the human security agenda. According to Martin et al., the whole-of-society approach can be described along two axes: first, it encompasses the integration of different needs and actions across a wide range of security needs, which can be described along a horizontal axis, linking security, human rights development and other areas, in a holistic way. This also brings together civilian and military tools and capacities. Second, a vertical axis links multiple stakeholders and actors and different levels of action (international, regional, nation state, local, etc.). ${ }^{7}$

In the context of analysing the EU's peacebuilding and conflict prevention capabilities, applying a normative and prescriptive ideal of 'whole-of-society', as described by Van der Borgh: "pays attention to the role of local societies, to multiple relationships at policy level and on the ground, and a wide range of stakeholders in the conflict space. The term whole-of-society refers to a set of ambitions of EU (and other) policy makers to work in a comprehensive and inclusive manner". It is, therefore, framed in a way that links clearly to the EU's (normative) ambitions, and indicates problem-solving possibilities to adapt EU practices.

The whole-of-society approach has local ownership as one of its underlying tenets. It can be defined as: "a normative concept, which envisages that local people control reform and reconstruction processes in the context of an external intervention. It includes attempts to bring together policy-level initiatives and perspectives with the views and expectations of end-users of security among populations in conflict-affected societies". ${ }^{\prime 2}$ The term local ownership has to some extent become a buzzword in the field of conflict prevention and peacebuilding. It has become accepted in literature and policy documents not only as a desirable imperative, but even as a precondition for successful international interventions in the areas of peacebuilding and state-building. ${ }^{10}$

Considering the ambiguity of the concept, Vesna Bojičić-Dželilović suggests its utility as a policy idea/ideal or guiding philosophy, rather than as an objective goal or tangible out-

6 Schirch 2016, 87. According to the work of Schirch et al: "Whole of Society refers to the need for diverse stakeholders at all levels of society to work together, as no one stakeholder can solve all of the problems in a complex environment and all must contribute according to their roles and responsibilities".

7 Martin et al. 2016, 13-15.

8 Van der Borgh et al. 2017, 5.

9 Martin et al. 2016, 60.

10 Ejdus 2017, 3. 
come of international intervention. ${ }^{11}$ Her work proposes to consider the relational and contextual nature of the concept, and to focus on how local ownership may emerge from the shared experience of external and local actors. ${ }^{12}$ The approach is not only about the outcome, but more a process of dialogue and relationship-building, which is similar to the human security approach. ${ }^{13}$

To go beyond the concepts of buy-in and local ownership, we may look at the level of inclusivity in processes related to peacebuilding and conflict prevention (programming or policies). Inclusivity refers to the 'how' of implementing local ownership. For actors to own the process rather than just remain at the receiving end of it, requires a degree of inclusivity. Dudouet and Lundström have defined inclusivity as "the degree of access to the various arenas of political settlements by all sectors of society, beyond the most powerful (pre-war) elites - both by participating (directly or indirectly) in decision-making and by having their concerns addressed by the state". ${ }^{14}$ Though their work mainly focuses on political settlements, it helps understand the concept and unpack the assumptions and ideas underpinning it.

In addition, they distinguish between horizontal and vertical participation. The first is referring to key stakeholders who have the capacity to implement and/or spoil peace and who represent important constituencies (considered part of the elite or traditional sources of power). The second relates to the extent to which larger segments of the population have access to/influence over decision making, with a specific emphasis on (previously) marginalised societal sectors (such as indigenous populations, women, and distinct ethnic groups) ${ }^{15}$

There are some assumptions concerning the benefits of inclusivity; the more inclusive, the better. ${ }^{16}$ The work of Dudouet and Lindström unpacks some of the normative aspects or values associated with it. These include legitimacy, which is related to inclusive (public) participation in decision-making processes; empowerment (of marginalised actors), effectiveness, and stability and resilience. This is based on the assumption that exclusionary or elitist outcomes may contribute to conflict and fragility in the long term. Besides the normative, or value driven reasons for striving towards inclusivity, some authors also framed it as "a pragmatic method to reach strategic gains, such as social legitimacy, that might later translate into increased bargaining power at the negotiation table or elec-

11 Bojicic-Dzelilovic 2016, 15.

12 Ibid., 9.

13 Wall et al. 2014, 122.

14 Dudouet and Lundström 2016, 8.

15 Ibid., 9.

16 Ibid., 10. 
toral support in the post-war era. Inclusivity can thus be described as a principle and a method...." ${ }^{17}$

Peacebuilding practitioners have noted that the implementation of local ownership is limited because of conceptual confusion, due to a poor articulation of the concept. The lack of shared understanding among international stakeholders and local counterparts limits its use at an operational level in day-to-day operations. ${ }^{18}$ Literature suggests that these differences in understanding can lead to unintended - counterproductive - consequences in peacebuilding outcomes. ${ }^{19}$ The fifth section of this article elaborates on the limitations of attempts to operationalise the concepts of local ownership and inclusivity. Integration of civil society ${ }^{20}$ is typically perceived as evidence of local agency and ownership. While this may not necessarily be a linear relationship, they are interlinked. Civil society organisations often constitute an entry point for community engagement. This is also the case in Mali, which I will cover in section 4.

As for the EU, the EU Global Strategy of 2016 makes several important references to local ownership, setting the ambition for itself to "facilitate locally owned agreements and commit long term". ${ }^{21}$ Also many other programmatic and policy documents include references to local ownership and inclusivity, even one document describing the former as "inherent in the European approach to international relations" ${ }^{22}$ However, it seems to effectively combine top-down and bottom-up approaches, citing "sustainable statehood rooted in local agency".23

In the EU's Joint Communication on Capacity Building in support of security and development of 2015, it is specifically stated that "EU support to security sector capacity building needs to be underpinned by EU external action principles. [This includes] ownership by the partner country...., and it is important to "use context analysis to prevent offer-

17 Dudouet and Lundström 2016, 20.

18 Van der Borgh et al. 2017, 40.

19 Bojičić-Dželilović 2016, 14.

20 Cited from Schirch 2016, 67. References to the term 'civil' imply a homogeneous group - as does 'the military'- but it is important to be aware of the differentiation within each category. For the 'civil' side, it often refers to civil society organisations (CSOs), NGOs, and humanitarian and peacebuilding organisations, among others, while there is a broad range and diversity of the types of civil society groups. Without going into much detail on definitions, the most important distinction is between humanitarian and multi-mandate NGOs, because of the differences in the degree, level and type of engagement with the military. On the one hand, humanitarian NGOs' aim is to provide aid to alleviate immediate suffering after a crisis, such as the provision of health care, and they have a clear framework under International Humanitarian Law. On the other hand, multi-mandate NGOs usually have broader and more long-term objectives, focused on root causes of conflict, and changing political, social and economic structures of societies, which may include mediation and peacebuilding.

21 EU 2016c, 18.

22 EU 2008, 3.

23 Ibid., 31. 
driven capacity building support". ${ }^{24}$ This begs the question whether the EU deliberately referred to 'partner country' as the one to own, instead of "local". In any case, the EU's ambitions in the direction of the integrated approach and more coherence should not be at the expense of local ownership, as noted recently by Tardy. ${ }^{25}$

Civil society is a recipient of crisis management and it provides support to enhance the effectiveness of EU CCM, in training of staff carrying out CCM activities and the development of training materials. Reasons for aspiring cooperation with the civil society lie also in its transparency and accountability. Further, its link with the wider population is relevant as they are not, necessarily, perceived as government representatives. The ability of CSDP missions to generate local ownership or buy-in is crucial to the EU. ${ }^{26}$

\section{Civil Military Synergies in External EU Action}

The need for "civil-military synergy" became an important factor in the EU's approach to crisis management and peacebuilding since the Nice European Council meeting in 2000, even though the term remained undefined..$^{27}$ In a general sense, the specific term 'synergy' is not as widely used as civil-military cooperation or coordination (and variations of these). Nevertheless, the EU Global Strategy on Foreign and Security Policy (2016) cites civil military synergy as a key part of its ambitions and affirms its plans to develop it further across its policies, as it is crucial for the EU's credibility and effectiveness. ${ }^{28}$ While there can be some debate on defining this concept, for the purpose of this paper I have chosen to draw on the work of Jayasundara-Smits (2016), who adopted the following working definition on civil-military synergy:

a combined or cooperative action of civilian and military actors, tools, goals and processes who together increase each other's effectiveness at strategic, tactical and operational levels of an EU operation. Also, civil-military synergy could mean the civilian and military arms in the comprehensive approach (CA) functioning together to produce a result (effectiveness) that cannot be independently obtainable by either.

Interestingly, during a roundtable discussion focused on civil-military synergies in EU action, ${ }^{29}$ it was confirmed by both civilian and military actors that in practice they did not use the term 'civil-military synergy'. They spoke more about coordination, cooperation, at

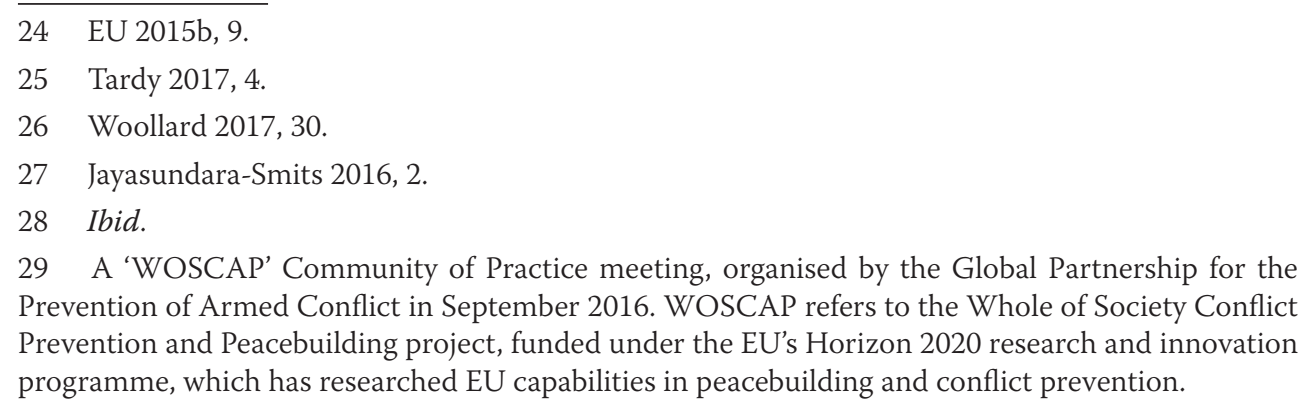

29 A 'WOSCAP' Community of Practice meeting, organised by the Global Partnership for the Prevention of Armed Conflict in September 2016. WOSCAP refers to the Whole of Society Conflict Prevention and Peacebuilding project, funded under the EU's Horizon 2020 research and innovation programme, which has researched EU capabilities in peacebuilding and conflict prevention. 
times even integration and effectiveness, as more useful terminology. Synergy seems to be more of an outcome of one of these actions, related to the overall goal of missions or interventions. The lack of a clearly defined concept on civil-military synergy was not an issue for the practitioners at the operational level. In fact, room for operational flexibility, which this seemed to imply, was seen as an advantage. ${ }^{30}$ They underlined the fact that there are already existing concepts intended to produce the same results. Therefore, they were also critical about the added value of the newly introduced concept of 'integrated approach' cited in the EU Global Strategy 2016, as a follow up of the 'comprehensive approach."31

Civil-military synergy is part of the evolution of the EU's civilian crisis management (CCM) ${ }^{32}$ Of its CSDP interventions, the EU has launched 21 civilian missions and 15 military missions or operations. ${ }^{33}$ While an overwhelming amount of literature is focused on CSDP interventions, one must consider the EU's other activities aimed at promoting peace and security in fragile states through its various funding instruments such as the Development Cooperation Instrument (DCI) and the Instrument contributing to Stability and Peace (IcSP). The EU Global Strategy indicates that it wants to: "(...) [S]trengthen operational planning and conduct structures, and build closer connections between civilian and military structures and missions, bearing in mind that these may be deployed in the same theatre" ${ }^{34}$ Moreover, it is clear that civil-military synergy is an important part of the EU's ambitions to act in an integrated way, especially when it refers to the multiple levels and dimensions outlined in the Global Strategy. In recent times, following the Global Strategy, significant institutional structures have been introduced to enhance cooperation and coordination, especially in the area of military capabilities, such as the Permanent Structured Cooperation (PESCO) on security and defence. These political and institutional changes suggest a greater interest and move towards a coherent CSDP, which could lead to overall EU capability enhancement, according to Sweeney and Winn, but it is not clear how this will foster more 'synergy' with the civilian capabilities..$^{35}$

While there is enough to be debated about what 'synergy' means, even the use of 'civilmilitary' as a dichotomy is increasingly coming under scrutiny. Within the scope of the EU, it could be said that everything that is not military is by definition civilian - thus, as described by Tardy, civilian crisis management is defined by what it is not, and brings together all crisis management activities that are of a non-military nature, including policerelated ones. ${ }^{36}$ However, the distinction becomes blurred when, for instance, the police do

30 Jayasundara-Smits 2016, 4.

31 Ibid., 5.

32 Tardy 2017, 9. Citing Thierry Tardy: "Civilian crisis management (CCM) describes a policy which involves the use of civilian assets to prevent a crisis, to respond to an ongoing crisis, to tackle the consequences of a crisis or to address the causes of instability".

33 EEAS (a) 2017.

34 EU 2016c, 18.

35 Sweeney and Winn 2017, 7-16.

36 Tardy 2017, 10. 
military-like activities or when a civilian mission predominantly has military staff. ${ }^{37}$ The civil-military distinction is called into question also beyond the EU, for instance when discussing the role of the police and private military actors. ${ }^{38}$ It may instead look more like a spectrum, with actors that share overlapping functions or imperatives. For this reason, it may be more useful at times to refer to the 'security sector', rather than the military. In a recent study by EU ISS, ${ }^{39}$ it is even argued that these issues may prove the need for a new paradigm in CCM to factor in civil-military relations. ${ }^{40}$

\section{The EU's Civilian and Military Efforts in Mali}

The security context in the Sahel, and Mali in particular, is intrinsically linked to development problems ${ }^{41}$ Based on the crisis that erupted in 2012 with the rebellion and advancement of Jihadist terrorism in the North of the country, many international interventions were developed to tackle the main security issues. The context in which these interventions are taking place creates significant obstacles, stemming from transnational crime, governance and democracy deficits, lack of rule of law, armed groups and terrorism. ${ }^{42}$ The EU and its Member States, notably France, provided political, logistical, and operational support in the fight against terrorist groups in northern Mali. There however remains a question of how SSR will be shaped in Mali, as it takes place in the context of chronic insecurity, and the multiplicity of external SSR programmes (in addition to the Mali government) which need to be well coordinated. It is not surprising that, according to a training expert in the police in Mali, there seems to be more of a rivalry between external partners than coherence. ${ }^{43}$

The EU established two interventions in Mali that seek to support and build capacity in the security sector. The EUTM Mali, which focuses on training the armed forces, and the European Union's Civilian Mission in Support of The Malian Internal Security Forces (EUCAP Sahel Mali). This section builds on a number of recent research findings ${ }^{44}$ on these missions and the author's interviews.

\footnotetext{
37 Ibid.

38 Jayasundara-Smits 2016, 6.

39 Tardy 2017, 10.

40 Ibid.

41 EEAS, strategy for the security of development in the Sahel region; eeas.europa.eu.

42 Gakou 2016.

43 Djiré et al. 2017, 45.

44. For a more exhaustive overview and analysis of the EU's peacebuilding capabilities in Mali, including multitrack diplomacy and governance reform, see: Djiré, Sow, Gakou, and Camara. 2017. Assessing the EU's Conflict Prevention and Peacebuilding Interventions in Mali. Université des Sciences Juridiques et Politiques de Bamako.
} 
The Malian state asked for support from the EU in reconstructing the Malian army. In December 2012, the EU set up a training mission for the Malian military through the European Union Military Training Mission - a military CSDP mission - aimed at contributing to the training and raising the standards of the Malian armed forces.

The EUCAP Sahel Mali civilian mission, ${ }^{45}$ launched on 15 January 2015, focused on helping the Malian government with the reform of its internal security forces. The mission provides experts in strategic advice and training to the Malian Police, Gendarmerie and National Guard and the relevant ministries in order to support reform in the security sector.

In addition, "EUCAP Sahel Mali supports the desire of the Malian state to modernise its security forces and enable them to respond more effectively to the need for protection of the entire Malian population throughout the country" ${ }^{46}$ It also states that it works in close collaboration with international players in Mali, and "alongside civil society as it will have a key role in supporting the reforms introduced by the government and ensuring they are understood by the public" ${ }^{47}$ Concerning the level of awareness, it is clear from various sources that the general public does not really know what the EU is doing in Mali and what security issues missions seek to address. More often they have heard about what some of the member states are doing, such as France or the Netherlands. This was confirmed during meetings in Bamako, ${ }^{48}$ where the EU's activities in the country were debated with civil society and academics. Consequently, the national media expressed the need to do more to increase awareness among the population and asked for additional interviews with EU representatives and Malian academics. In order for the public to understand the reforms, the EU would have to take additional action to increase the awareness. Public understanding of the EU's role is part of creating local accountability and legitimacy.

EUCAP states that it supports the "contribution of civil society to designing the reforms, and in parallel civil society brings its experience to the implementation of EUCAP's activities" ${ }^{49}$ While there is a long history of coordination mechanisms in Mali, which is at times criticised as being externally initiated or non-transparent to local CSOs, there is an example of good practice. The Plateforme d'Echange et d'Action set up by EUCAP-Sahel brings together Malian security forces with CSOs working on security and international partners, chaired by a civil society participant. It serves as an entry point for collabora-

45 EUCAP Sahel Mali objectives: Re-establishing their respective hierarchical chains; Reinforcing the role of judicial and administrative authorities with regard to the management and supervision. of their missions; Facilitating their redeployment to the north of the country. See: EEAS (b) 2016, EUCAP Sahel MaliFactsheet.

46 EUCAP Sahel Mali (a) 2017, par.3.

47 EEAS (b) 2016, 2.

48 After a roundtable in Bamako where the EU's activities in the country were debated as part of the Horizon 2020 project WOSCAP.

49 EUCAP Sahel Mali (b), par. 19. 
tion, for example on integrated training. Such examples can be a way to build personal relationships and trust over time, alleviating some of the coordination challenges in the longer run. ${ }^{50}$ By its military nature (and more remote location), the EUTM has less of an engagement with civil society.

As mentioned, the EU is increasingly developing activities that focus on internal security, which it links to external threats, for instance in the case of counter-terrorism efforts and migration. Internal security objectives are increasingly influencing mandates for external (CSDP) interventions, which is also seen in Mali. ${ }^{51}$ From the research by Djiré, it appeared that the EU saw working with moderate non-state actors as a way to weaken the influence of extremist and armed groups in Mali, even if such practice was in breach of the EU's official policy. ${ }^{52}$ After a strategic review of the mission, in 2017 the mandate was updated to strengthen the original mandate, adding the following components (amongst others): "Strengthen the internal security forces' capacity in the fight against terrorism and organised crime; Support Mali in managing migration flows and border management".53 Moreover, the military training mission EUTM Mali has as an explicit objective to "neutralise organised crime and terrorist threats" ${ }^{54}$ To some extent, it is understandable that the EU should place more emphasis on security objectives, and this is also explicitly mentioned in the EU Global Strategy. At the same time, it may provoke mistrust on the part of the partner country if those targets are prioritised too much, which may hamper continuation of the mission. ${ }^{55}$ CSDP interventions, which would for example explicitly focus on migration that is of primary concern to the EU, would not be perceived as the most appropriate response to local needs. Equally, CSDP with a sole focus on countering terrorism can divert attention to equally important disrupting factors. The challenge is to strike the right balance between the EU's own security agenda and the needs of the beneficiary population. ${ }^{56}$

Despite all the investments into the Malian state apparatus and civil society projects, the sense of security in Mali has deteriorated since 2015. A majority of respondents in a recent survey among Malian civil society conducted by SIPRI perceived deterioration in the security situation, and felt that "violence has increased since a year ago" ${ }^{57}$

How different actors are positioned and perceived locally needs to be taken into account in the phase of planning and design of interventions if they are to respond to people's

\footnotetext{
50 Aulin and Divin 2017, 13.

51 Zandee et al. 2015, 37.

52 Van der Borgh et al. 2017, 44.

53 EEAS (c), par. 9.

54 EUTM Mali, par. 2.

55 Zandee et al. 2015, 37.

56 Tardy 2017, 19.

57 Tobie 2017, 5.
} 
needs. ${ }^{58}$ Surveys have shown that security is perceived differently by women and men and also differently across the regions in Mali, which will require targeted and specific implementation of the Algiers Peace Agreement. This can help decision-makers adapt their policies to their needs, better meet expectations, as well as inform the division of roles amongst internationals. ${ }^{59}$ However, the planning process of CSDP missions is currently a rather top-down exercise, and CSDP missions are driven by political considerations of Member States rather than their achieving more effectiveness, as argued by Boštjančič Pulko. As a result, prolonged decision-making processes regarding the planning and mandates of CSDP missions have resulted in compromises at the cost of on-the-ground needs and those of the host countries. ${ }^{60}$ External interveners who want to promote local ownership still often place the state at the core and focus on state-building. Re-establishing the authority of the state across the entire territory in Mali is an important priority. While this is also part of the 2015 Algiers Peace Agreement, at the same time it explicitly calls for a greater degree of local decision making to adapt policies to local realities. ${ }^{61}$ While the focus on the state makes sense, it can in some ways also become an issue. For instance, strengthening the state through militarised or state building efforts can be seen as perpetuating part of the root causes of the conflict, especially when government malperformance is part of the structural causes of the conflict. Furthermore, in Mali, traditional and religious structures are at the heart of social cohesion and governance, which may operate in parallel with formal state structures. A state-centric approach may not factor this in, while these informal structures must be taken into account as part of a 'hybrid' vision of state-building. ${ }^{62}$

A recent research report notes that "though Mali's ownership is considered key to the success of support, the political and bureaucratic requirements of the international actors, as well the complexities of the support architecture, actually make it very challenging for the Malian State to exert leadership and control in the whole process". ${ }^{63}$ Lastly, there was the creation of the Conseil National pour la Réforme du Secteur de la Sécurité in August 2014, to deal with SSR at the national level, which should arguably be a national central point for bringing together or creating coherence between the various international SSR interventions. However, this will be difficult as long as it continues to face internal challenges to function. This also begs the question to what extent and when this could be reinforced or supported through EUTM and EUCAP Sahel missions.

Both EUCAP and EUTM face serious challenges in providing training, on multiple levels. One of the key questions for the military training mission will be how to take into account

\footnotetext{
58 Aulin and Divin 2017, 7.

59 Tobie 2017, 2-12.

60 Boštjancic Pulko 2018, 147.

61 The Algiers Peace Agreement mentions the establishment of a national or local police force. It is not yet clear what this means and how it will be implemented.

62 Aulin and Divin 2017, 8.

63 Djiré et al. 2017, 27.
} 
the context and 'intangible', human factors better. A civilian trainer contracted by EUTM mentioned that the factor of revenge in the north (for what happened during the crisis) is a real problem. Crimes are committed, also against women, despite the training in International Humanitarian Law (IHL) and efforts to prevent gender based violence. Bias and discrimination prevail in different layers of Malian society. The key question is how to shape a programme that can take into account these deeply rooted issues - and work in synergy with other mechanisms (civilian ones) to tackle them. In addition, trainings were also found to be based on some assumptions originating from European military structures and culture. For instance, leadership and hierarchy in the Malian military are not experienced in the same way, which causes gaps in training. As noted by Gakou, these issues require greater support at the national level by including them within the framework of Malian national strategies for the military and police functions. ${ }^{64}$

While it was found that overall EUTM trainings had increased the skills of Malian soldiers, one of the noted shortcomings was that EUTM staff "could have done more to use local expertise and adapt the training to the Malian context". ${ }^{65}$ The degree of exposure to International Human Rights Law, Humanitarian Law, and prevention of gender based violence is quite limited, though improving. It is also quite a challenging environment, which requires taking into account more of the human elements. One of the trainers at the EUTM shared that one of their main frustrations was the inability to go to the north and monitor and evaluate whether the trainings were actually useful in the field. Speaking to someone working for MINUSMA and involved in drafting the Algiers Peace Accords, this had to do with staying away from each other's respective mandate area. This inhibits effective monitoring and evaluation of the trainings. Nevertheless, there was temporarily a good practice of sharing expertise between EUTM and MINUSMA, using UN monitors to report on the behaviour and performance of EU-trained Malian soldiers in the field, as they were already doing this kind of work. This however, did not continue.

Recent research on the EU's SSR efforts in Mali noted that to build a new security structure, the need for adapting the organisations and operations to the security needs of the country calls for the establishment of effective democratic control over the security sector by "improving the effectiveness of parliamentary committees, strengthening judicial authority and the checks and balances provided by civil society; the development of a human security framework which supports lasting human development".66 This would imply 'civilianising' security by opening up the security sector, making it transparent, and subject to public and civil control. ${ }^{67}$ This supports the calls for the EU to move from its predominantly 'train and equip' approach in practice, to a comprehensive governancedevelopment approach, as implied in some of its policy documents such as the EU's 2015

\footnotetext{
64 Gakou 2016, 13-17.

65 Djiré et al. 2017, 42.

66 Djiré et al. 2017, 55.

67 Ibid.
} 
Joint Communication on Capacity building in support of security and development (also called the 'CBSD'). ${ }^{68}$

As a positive development, the training programmes of both EUTM and EUCAP were designed in part on the basis of local inputs, which strongly enhanced the quality and relevance of the trainings. Still, the missions could benefit from a more systematic inclusion of dialogues and training by Malian academic institutions, national UN offices such as the UNDP, and local civil society. ${ }^{69}$ Some drawbacks, as identified in the research by Djiré, were summarised as "the occasional discontinuity between training modules, insufficient coordination and coherence in the training offered, language barriers between trainers and trainees, and the significant differences in quality between the trainers in charge. This [...] points at the need to step up participants' training evaluation measures"70

\section{Challenges for the EU in Working Towards Local Ownership in Ca- pacity Building Efforts}

This section aims to identify some of the key limitations to achieving local ownership in the EU's civil-military synergy and also discuss their potential risks and implications. Some of these are inherent to most international peacebuilding interventions. First, there are limitations to the ideas of local ownership and the principle of inclusivity, both conceptually and in practice. One of the limitations of 'whole-of-society' and inclusivity is that it is difficult to exploit improved integration and synergies between a growing amount - and diversity - of groups and processes. ${ }^{71}$ At times, local ownership is understood as national ownership. 'Ownership' is at times conflated with 'buy-in', and agreements between the donor and beneficiary country are sometimes only a means to enhance national buy-in, and not to enable local actors to be part of programming of the activities or influence decisions. ${ }^{72}$ Thus, it raises questions about what is meant by "local"; who does this include? As was seen in Mali, there was buy-in and support from the Malian state, but it cannot be said that the processes that the EU had designed were locally owned in reference to the population. Furthermore, the strengthening of the state brought along other dilemmas.

Second, there is an inherent tension between the tangible and less tangible dimensions of local ownership. There are clear efficiency objectives from the EU, derived from its priorities, logframes, targets, timelines, funding requirements and guidelines. This stands in contrast to the need to engage in processes that are consultative, participative and adaptive, intended to ensure inclusivity and develop relationships that foster local ownership

68 EU 2015b.

69 Aulin and Divin 2017, 8-9.

70 Djiré et al. 2017, 56.

71 Van der Borgh et al. 2017, 6.

72 Bojičić-Dželilović 2016, 14. 
and sustainability. ${ }^{73}$ There seems to be a level of consensus in the field of civil-military synergy on the need for trust building and human relationships. There is to some extent a tension in that external interventions focus on assisting formal institutions, structures and specific actors, while the key components of rebuilding these institutions and their legitimacy lies in relationships of trust, reconciliation and confidence. ${ }^{74}$ There is also a challenge in overcoming a degree of suspicion or unwillingness on the receiving end of an intervention. ${ }^{75}$

Third, the mandates of external interventions or the design of projects and programmes are not just a product of good intentions, but are part of - and influenced by - a political context, with pressures that often result in a compromise. Research by Van der Borgh et al. shows that several EU missions have been the result of deals and compromises made between the EU Member States, as well as with the host country, subject to pressure from national electorates, geopolitical tensions, and negotiations within governments. ${ }^{76}$

Fourth, in some cases there is not merely a discrepancy in expectations and outcomes (as above), but also a difference between what the EU has identified as the benefiting country's needs (which is also a political decision) and what that country wants or expects the EU to deliver.

Another set of challenges presents itself when specifically looking at engaging civil society, as part of 'inclusivity' efforts. A recurring challenge for most international intervening actors is the selection of local interlocutors. Often, 'who to engage with' is chosen through an externally conducted conflict analysis with limited local input, and based on visibility of local CSOs - who are often elitist, 'Western', and institutionalised. This may bypass important constituencies which often have strong standing in local communities, which can serve as bridges between various groups and levels in society. ${ }^{77}$

Issues of trust and relationships also play out in civil-military engagements. Most actors agree that enhancing the level of sharing information will be increasingly crucial for the success of civilian and military endeavours. Nevertheless, prevailing obstacles stem from a lack of trust and not knowing how the information will be used, not knowing what information is collected and how, and different understandings of what can be shared without confidentiality and safety restrictions. In informal settings these barriers seem to be less of an issue, but still have an impact.

Factors that are difficult for the EU to influence, but that significantly affect the ability to realise synergies, include the operational environment (stable/volatile), and longer vs.

73 Van der Borgh et al. 2017, 40.

74 Bojičić-Dželilović 2016, 7.

75 Schirch 2016, 88.

76 Van der Borgh et al. 2017, 37.

77 Ibid., 40. 
shorter term missions and presence. Longer-term SSR missions that operate in a context crowded with actors, policies, agendas and interests are more challenging. ${ }^{78}$ Compared to the military side, on the "civil" side there are many more actors to engage with, and the "jungle" of civilian organisations can make it hard for military actors in the field to keep different organisations and their activities apart.

As also stated in the EU global strategy, the EU will increasingly link its internal security objectives with the external ones, and develop activities that focus on internal security such as counter-terrorism and border surveillance. ${ }^{79}$ This is to avoid risks of spill-over effects, from insecurity outside of the EU, as we also see in the case of Mali. However, there are some implications that need to be considered. CSDP missions that focus on migration would not necessarily be perceived as responding to local needs.$^{80}$ There is a risk of the attention and weight of civilian priorities shifting into the direction of fighting transnational organised crime, border control and migration issues, because this is currently high on the European political agenda, at the expense of investments in local peacebuilding activities that focus on tackling the root causes of these phenomena and 'social change'. It remains to be seen how this part of civilian crisis management will develop alongside the existing support to activities at the level of conflict prevention, peacebuilding and development. ${ }^{81}$

Moreover, civil-military synergy may imply 'integration' on the operational level, but it is useful to unpack further and distinguish what is understood by 'integrated' and synergy in both the civil and military sense. While there may be reasons to desire a degree of integration of some aspects (planning or the interoperability of communication systems), it may not be necessarily desirable to integrate the two domains, as they remain inherently distinct entities. It may be more useful to focus on what the synergetic outcome should be (common goals), before focusing on how to integrate the means to get there. ${ }^{82}$

In order to reflect on the opportunities for the EU civil and military interventions to be more inclusive, we should consider the potential outcomes of EU and civil society working together in this area, and specifically capacity building in the security sector. There may be harmful consequences to the military always being required to be embedded in local contexts and among the local civilian population. Being visibly together could cause serious risks to the population for their seeming collaboration with the 'enemy' forces. ${ }^{83}$ In addition to the risks, it should be asked to what extent local civil society is instrumentalised as part of for instance 'hearts and minds' strategies.

\footnotetext{
78 Jayasundara-Smits 2016, 17.

79 Zandee et al. 2015, 37.

80 Tardy 2017, 19.

81 In the NGO sector there are concerns that the move in this direction constitutes a move towards the securitisation of civilian / peacebuilding issues.

82 That said, the creation of the Military Planning and Conduct Capability (MPCC) and move towards having one headquarters is a welcome step towards civil-military synergy at the Brussels level. 83 Jayasundara-Smits 2016, 12.
} 
If the EU wishes to enhance its work in peacebuilding and crisis management, benefits lie in monitoring, reviewing, evaluating and learning from its interventions and activities. There is a search for good examples or best practices in this field, where the lists of challenges seem endless. Specific to the area of civil-military cooperation is the fact that this is a sensitive area of work, especially on the operational level. As a consequence, there is a limited amount of documentation on good examples. These are shared informally, but there is a risk in publishing or formalising them, or including specifics. Civil society practitioners, government officials and military personnel highlight and agree that public or formal documentation of ground-level best practices is not desirable when it carries risks for the civilian actors who take part in them, or when they are in breach of formal procedures and confidentiality agreements (usually military). ${ }^{84}$

In addition, in interviews and discussions with EU officials it became clear that some were more convinced of the need for local ownership than others. It ranged from those emphasising the importance of local views being taken into account when designing current or new missions, and the funding of more projects that capture the perceptions of beneficiary populations on the one hand; to those, on the other, who do not even mention the topic (more technocratic focus), and some who seemed to altogether dismiss the idea of a local perspective as an indicator. There was a debate on how much 'weight' the locals' opinions have to indicate success of a mission. The lack of agreement indicates that combining both top-down and bottom-up approaches would be useful to link the different perspectives.

Furthermore, there is a difficulty in assessing what is needed, and there is a risk that locals will not accept whatever the EU proposes. It takes time to achieve mutual understanding, and while there is an awareness of this among the policymakers, time is not on their side. Nevertheless, there are some good examples that show how this can be done, such as the two-year process that the Netherlands undertook with Burundi, which resulted in an MoU concerning a long-term commitment and engagement. ${ }^{85}$

\section{Opportunities for the EU}

This section describes the opportunities and directions the EU could take to tackle some of the challenges discussed above, focused on the operational level. This part is not meant to idealise these as solutions since, from a whole-of-society perspective, solutions will remain tied to "context, context and context". As we can see in the case of Mali, the understandings and experiences of (in)security are different across different sections of society, regions and gender, and a national approach cannot address them sufficiently. To achieve local ownership, we must consider all facets of society. ${ }^{86}$ As civil society - at different levels - is one of the main interlocutors for the EU to engage through and with local ac-

84 Jayasundara-Smits and Vogelaar 2016.

85 Ball 2014. 7.

86 See work by Vesna Bojičić-Dželilović in Bojičić-Dželilović 2016. 
tors, this section will elaborate on ways in which the EU could further benefit or deepen its relationship with it.

The EU aims to take on a more comprehensive approach to SSR, ${ }^{87}$ which requires applying a broader set of tools and engagements in a country than just CSDP, embedded in aspects such as governance reform and development. ${ }^{88}$ The EU needs to do more to shift the current emphasis on 'train and equip' to a more holistic, developmental approach, in the civil- and military domains. ${ }^{89}$

There are several areas in which the EU can strengthen civil-military synergy and cooperation, specifically with civil society. Civil society and the security sector can carry out joint implementation in a wide range of efforts in diverse sectors, including community policing, protecting civilians and more. Joint monitoring and evaluation of security sector performance in oversight mechanisms, including consultations informing security priorities and feedback on military interventions can be useful..$^{90}$ Activities such as planning together foster working relationships and provide space to build trust. They can be considered interim pillars or 'means' toward a civil-military synergy. ${ }^{91}$ The EU Global Strategy already provides concrete proposals for civil-military tasks and capability priorities, one of which is investing in better and shared assessments of internal and external threats and challenges. ${ }^{92}$ The EEAS' current capacities for conflict analysis and conflict sensitivity are relevant in this regard, and should be strengthened.

From a whole-of-society perspective, accountability and inclusive feedback mechanisms are important parts of increasing local ownership. With the EU missions in Mali it is not clear how these mechanisms are ensured. From there, the next step would be institutionalised platforms for civil society involvement in the oversight, monitoring and evaluation of the security sector, with the aim to ensure that there is accountability and local ownership. Regular or institutional engagement is a way to work towards an accountable, democratic state response. ${ }^{93}$ In the case of Mali this may require more time, but the EU needs to think about how to support the government in setting up such processes in the long run.

$87 \quad$ EU 2015b.

88 See Tardy 2017.

89 The EU's Joint Communication on capacity building in support of security and development is a step in the right direction, but civil society has voiced concerns about how this will actually be implemented in practice, and whether it will be less of a 'train and equip' approach. This remains to be seen with Mali as one of the pilot cases.

90 As evidenced in Schirch 2016, 95; Schirch 2015, 25; Jayasundara-Smits and Vogelaar 2016.

91 See Jayasundara-Smits 2016; Schirch 2016.

92 EU 2016c, 44.

93 Schirch 2015, 26, 71. 
Taking into account the 'whole-of-society' approach demands increased efforts to embed local realities, and working together with local populations. ${ }^{94}$ In the planning phase, the EU could design a task force to carry out small-scale exploratory missions that can afterward be scaled up, overseen by the EU delegations. In addition, involving local beneficiaries in the planning and designing phase of missions would decrease the gap between the priorities set by EU Member States, and addressing the needs of the local population and national beneficiaries. Taking the time to negotiate without pressure can lead to a better outcome, but time is not always on the side of the policymakers.

There are seemingly large differences in skills and expertise between staff that is seconded by different Member States, which became clear in the EUTM. An important opportunity for the EU in this regard is to set up more focused training programmes for seconded EU staff prior to their participation in an EU SSR mission. There is room for Member States to improve their cooperation concerning pre-deployment training, and to build on the expertise of those among them that are more advanced. Moreover, the EU should try to involve previous staff, trainees and beneficiaries in pre-deployment training in a systematic way.

In assessing effectiveness, the subjective elements of perception and individual agency are increasingly seen as more important than the structural, procedural and bureaucratic ones. ${ }^{95}$ Trust building and networking is imperative for successful civil-military collaboration or cooperation at the operational level. However, developing personal contacts and trust building is especially challenging in short term EU missions and with frequent staff changes. Not to mention the loss of transfer of knowledge across the civil and military divide. Providing more frequent and regular opportunities for communication between civil and military actors, even without the presence of an external mission in immediate sight, was recommended as a good investment. ${ }^{96}$ Especially if the EU wants the population to understand the reforms, it should do more to inform and raise awareness about them among the local population, as their knowledge of the EU's efforts is very limited. Maintaining local relationships could be facilitated by better handover procedures of CSDP staff at leadership positions. Another possible way to counter the negative effects of frequent staff turnover would be to make the EU delegations in partner countries the main instrument for maintaining contacts with local stakeholders, as their longer presence can help bridge the gaps and they already have relationships with local CSOs. Furthermore, one of the outcomes of discussions on this topic was to recommend the EU to have a defence or security attaché as part of the EU country delegation. This attaché could advise at earlier stages on conflict prevention/analysis. ${ }^{97}$

94. Jayasundara-Smits 2016, 3.

95 Jayasundara-Smits 2016, 13.

96 Jayasundara-Smits and Vogelaar 2016.

97 These personnel can be drawn from former staff or retired military personneland should be integrated as EU diplomats. This idea is increasingly supported by some of the consulted governmental representatives. It was also mentioned in the report by Zandee et al. 2015. 
Another field where civilian and military cooperation can be enhanced is in engaging non-state armed groups, which seems even more relevant in recent times. With the EU Global Strategy making explicit reference to counterterrorism and countering violent extremism efforts, and linking the EU's internal and external security, it has been proposed as an area for enhanced civil-military synergy. ${ }^{98}$ However, it remains unclear in what direction the 'civilian' part would develop, as it will require complex set of dimensions. Civil society plays a role in mediating with non-state armed groups, facilitates youth conflict transformation trainings, and is increasingly involved in shaping ideas on countering violent extremism and prevention. Needless to say, there are risks and limitations involved, but this is an area where civil-military synergy has the opportunity to evolve. Nevertheless, civilian capabilities and engagement with these groups need to be taken into account beyond 'winning hearts and minds', which is usually focused on advancing military objectives.

The whole-of-society perspective also considers that capabilities are forged in interaction with other actors, creating opportunities in the "political or conflict context" in which the EU acts. ${ }^{99}$ This includes sharing experiences and expertise about SSR with other institutions and states, including the US, NATO, OSCE and the UN, and to have more structured cooperation in the beneficiary country. This is important to deal with diverging priorities and different approaches to SSR.

Bearing in mind the limitations outlined in the previous section, the EU could institutionalise previously mentioned possibilities for civil-military guidance in the form of a framework or space within which these interactions would become regular instead of ad hoc, and where actors could find each other more easily. For example, the EU can develop permanent civilian oversight mechanisms for its defence capabilities, to ensure responsibility of missions to European citizens on the one hand, and accountability towards the local populations on the other. But first, it should explore ways to develop flexible frameworks under which these spaces can grow, within which meaningful interactions can take place.

\section{Conclusion}

There is a significant gap between the EU's ambitions and policies for Security Sector Reform and the extent to which this is pursued or achieved on the ground. In practice, on the operational level, there is a focus on providing 'train and equip' type of capacity-building and support, while less attention is paid to certain aspects such as inclusivity and local ownership - which is also more challenging. It is less holistic and comprehensive, and is more of a top-down informed effort than an effort influenced by the context and local population. The EU also may not have the necessary means, resources and mandate to focus on the more 'intangible aspects', which creates a gap between expectations and reality.

98 As, for instance, by Snowy Lintern, in Lintern 2017.

99 Van der Borgh et al. 2017, 6. 
A good example was found in EUCAP Sahel with the civil society platform which can provide the necessary spaces and frameworks around which better relationships can be formed and greater trust established. However, there are inherent limitations to the normative ideal of 'local ownership' and inclusivity, which will remain a challenge for the EU and other actors. First, how local ownership is understood in practice can be problematic, especially when the 'buy-in' from the national government is considered sufficient to 'tick the box'. Second, the tension remains between achieving measurable results and engaging in long-term less-tangible processes and relationship-building to foster inclusivity and local ownership. Other factors include political context and gaps between the needs and political priorities of the EU and the beneficiary state.

In the area of civil-military synergies, there are also some important limitations that the EU needs to take into account in its ambitions toward a more integrated approach. First and foremost - should civil-military capabilities be integrated? Several issues have been raised in this regard, especially in linking internal and external security objectives. Second, there are key issues derived from the complexity of engaging civil society - whom to engage? - and there is a lack of understanding and guidance on how to work with various types of actors in peacebuilding and development, as well as others.

Opportunities and areas that the EU could explore further include collaboration in the area of monitoring and evaluation, and more inclusive civilian oversight and feedback mechanisms. Ways to overcome shortcomings in expertise, skills and training have been identified on the one hand, while on the other a broader strategy or framework for civilmilitary synergy will be needed, especially to overcome less tangible issues and challenges. Embedding missions in local realities is needed for realising civil-military effectiveness and sustainability on the ground. This may prove that there is a need for a new paradigm or framework in CCM to factor in civil-military relations.

Fragile and failing states pose a particular challenge for the EU, and Africa remains the most likely area of operations for the CSDP. The case of the EU's actions in Mali will continue to be relevant as the missions evolve and considering the fact that the complex context has not become any easier with the passage of time. It is likely that there will be a greater emphasis on capacity-building in the wider security sector and the nexus of civilian and military capabilities. The implementation of a whole-of-society or human security approach calls for protection and empowerment of populations, implying the need for both 'top-down' and 'bottom-up' measures. The EU's intention is to link these top-down and bottom-up approaches to achieve more effective results, but there is a lack of focus on the latter approaches in the case of Mali, where 'local agency' is not so evident. Only with a stronger focus on inclusivity and local ownership aspects of both civil and military action of the EU will it be able to better address the 'intangible aspects' of security sector reform.

Perceptions and trust all constitute key factors in the success of a civil-military synergy, and in international interventions more broadly. Additional research that focuses on 
enhancing the EU's peacebuilding capabilities should be done into what was referred to in the article as 'intangible', social elements. ${ }^{100}$ The human, or social, element is not as covered as some of the more tangible aspects (training, interoperability of systems), and therefore deserves more attention. Taking a whole-of-society approach or perspective is a useful way to explore this.

100 See: Ejdus and Juncos 2018. Reclaiming the local in EU peacebuilding: Effectiveness, ownership, and resistance, Contemporary Security Policy. 39 (1): 4-27. 


\section{References}

Aulin, Jenny, and, Divin, Charlotte. 2017. Towards Local Ownership of International Interventions in Mali. GPPAC Policy Note. 2017/1 (June). The Hague: Global Partnership for the Prevention of Armed Conflict (GPPAC).

Aulin, Jenny, and Vogelaar, Gabriëlla. Towards a Comprehensive Approach? Civil Society and Security Sector Perspectives on Dutch Missions. The Hague: Cordaid, GPPAC and Pax.

Ball, Nicole. Putting governance at the heart of security sector reform: Lessons from the Burundi-Netherlands Security Sector Development Programme. Conflict Research Unit, The Clingendael Institute. March 2014. https://www.clingendael.org/sites/ default/files/pdfs/Putting\%20governance\%20at\%20the\%20heart\%20of\%20SSR.pdf> , accessed 2 August 2018.

Bojičić-Dželilović Vesna. 2016. Owning the Peace in International Interventions: a Delusion or a Possibility? Scoping Study on Local Ownership. London: London School of Economics and Political Science.

Boštjančič Pulko, Ivana. 2018. (In)effective Planning Capacity of CSDP Missions: Comparative Analysis of EULEX Kosovo and EUFOR Althea. Journal of Regional Security 12 (2): 123-156.

Djiré, Moussa, Sow, Djibril, Gakou, Kissima, and Camara, Bakary. 2017. Assessing the EU's Conflict Prevention and Peacebuilding Interventions in Mali. Case Study Report Mali. Bamako: Université des Sciences Juridiques et Politiques de Bamako.

Dudouet, Véronique, and Lundström, Stina. 2016. Post-war Political Settlements: From Participatory Transition Processes to Inclusive State-building and Governance. Research Report. Berlin: Berghof Foundation.

Ejdus, Filip. 2017. "Here is your mission, now own it!" The rhetoric and practice of local ownership in EU interventions. European Security, DOI: 10.1080/09662839.2017.1333495.

Ejdus, Filip \& Juncos, Ana E., 2018. Reclaiming the local in EU peacebuilding: Effectiveness, ownership, and resistance, Contemporary Security Policy. 39 (1): 4-27.

EU. 2008. Security Sector Reform - draft document on deployable European expert teams, 14576/1/08 REV 1, Brussels, 21 October. 
EU. 2015b. Joint communication to the European parliament and the European council: Capacity building in support of security and development - Enabling partners to prevent and manage crises, JOIN (2015)17, Brussels, 28 April.

EU. 2016c. Shared vision, common action: a stronger Europe, a global strategy for the European Union's foreign and security policy, Brussels, June.

EEAS (a). 2017. Military and civilian missions and operations. https://eeas.europa. eu/headquarters/headquarters-homepage_en/430/Military\%20and\%20civilian\%20 missions\%20and\%20operations. Accessed 7 August 2017.

EEAS (b). 2016. Factsheet on EUCAP Sahel Mali. June 2016. http://eeas.europa.eu/ archives/docs/csdp/missions-and-operations/eucap-sahel-mali/docs/factsheet_eucap_sahel_mali_en.pdf. Accessed 29 July 2018.

EEAS (c). EUCAP Sahel Mali - About. https://eeas.europa.eu/csdp-missions-operations/eucap-sahel-mali/3900/node/3900_en. Accessed 2 August 2018.

EUCAP Sahel Mali (a). https://eucap-sahel-mali.eu/. Accessed 7 August 2017.

EUCAP Sahel Mali (b). Activities. https://eucap-sahel-mali.eu/activities_en.html Accessed: 7 August 2017.

EUTM Mali. 2015. http://eeas.europa.eu/csdp/missions-and-operations/eutm-mali/ index_en.htm. Accessed 7 August 2017.

Gakou, Kissima 2016 et al. Working Paper 2-3: Articles addressing current topics related to the EU from a whole of society perspective. The Hague: Global Partnership for the Prevention of Armed Conflict (GPPAC).

Jayasundara-Smits, Shyamika. 2016. Civil-Military Synergy at Operational Level in EU External Action. Best practices report. The Hague: Global Partnership for the Prevention of Armed Conflict (GPPAC).

Jayasundara-Smits, Shyamika, and Gabriëlla Vogelaar. 2016. Community of Practice Roundtable: Civil-Military Synergies in EU Action. The Hague: Global Partnership for the Prevention of Armed Conflict (GPPAC).

Jayasundara-Smits, Shyamika, and Gabriëlla Vogelaar. 2016. Time to Bite the Bullet: Fostering Civil-military Synergy in EU Crisis Management and Peacebuilding Operations. Research Gate. 
Lintern, Snowy. 2017. What civilian-military synergies? Recasting EU civilian crisis management. EU Institute for Security Studies. Report No. 31: 35-40.

Martin, Mary, Vesna Bojicic-Dzelilovic, Chris Van der Borgh, and Georg Frerks. 2016. Theoretical and Methodological Framework. London, London School of Economics and Political Science, and Utrecht, Utrecht University.

Tardy, Thierry. 2017. The new forms of civilian crisis management. Recasting EU civilian crisis management. EU Institute for Security Studies. Report No. 31: 9-22. https://www.iss.europa.eu/sites/default/files/EUISSFiles/Report_31.pdf.

Tardy, Thierry. 2017. The EU: from comprehensive vision to integrated action. EU Institute for Security Studies. Brief No. 5 (February).

Tobie, Aurélien. 2017. A fresh perspective on security concerns among Malian civil society. SIPRI Insights on Peace and Security. 2017/2 (July).

Schirch, Lisa (ed). 2016. Handbook on Human Security: A Civil-Military-Police Curriculum. The Hague: Alliance for Peacebuilding, GPPAC, Kroc Institute.

Schirch, Lisa, and Deborah Mancini-Griffoli. 2015. Local Ownership in Security: Case Studies of Peacebuilding Approaches. The Hague: Alliance for Peacebuilding, GPPAC, Kroc Institute.

Sweeney, Simon, and Neill Winn. 2017. "CSDP and the Open Method of Coordination: Developing the EU's Comprehensive Approach to Security." Journal of Regional Security 12 (2): 95-122.

Van der Borgh, Chris, Mary Martin, and Vesna Bojicic-Dzelilovic. (unpublished). EU capabilities in conflict prevention and peacebuilding: Challenges, strengths and opportunities of a Whole-of-Society approach. Research report. London, London School of Economics and Political Science, and Utrecht, Utrecht University.

Vogelaar, Gabriëlla, and Rick Hoefsloot, with inputs from Georg Frerks, and Toon Dirkx. Unpublished. A European Way to SSR? Why local ownership should be at the heart of the EU's SSR efforts. GPPAC Policy Brief. The Hague: Global Partnership for the Prevention of Armed Conflict (GPPAC).

Wall Kristen, Aulin Jenny, and Gabriella Vogelaar. 2014. Empowerment and Protection Stories of Human Security. The Hague: Global Partnership for the Prevention of Armed Conflict (GPPAC). 
Woollard, Catherine. 2017. "Civil society and civilian crisis management: Recasting EU civilian crisis management." EU Institute for Security Studies. Report No. 31: 69-75.

Zandee, Dick, Hans Hoebeke, Hans Merket, and Minke Meijnders, eds. 2015. The EU as a security actor in Africa. In-depth study Clingendael Monitor. The Hague: Clingendael Netherlands Institute of International Relations. 